\title{
Diamond substrate interactions and the adhesion of diamond coatings
}

\author{
Benno Lux, Roland Haubner \\ Technical University, Vienna, Austria.
}

\begin{abstract}
Formation of a diamond coating on a substrate requires a stable substrate surface, especially during early deposition stages.

In many cases hydrogen and/or carbon react with the substrate surfaces to form gases or solid carbide layers, to dissolve carbon, etc., leading to changes in the diamond nucleation and growth. Certain substrate elements with high vapor pressures can also cause detrimental effects.

Al] these interactions can affect the adhesion of the diamond coatings. Intermediate layers applied prior to diamond deposition might finaliy prove to be one of the best possible solutions for minimizing such detrimental substrate interface effects.

KEY WORDS: CVD diamond, nucleation and growth, vapor pressure, substrate/gas and diamond/substrate interactions, substrate surface treatments, intermediate layers, adhesion.
\end{abstract}

\section{INTRODUCTION}

Very few materials are inert to the aggressive gas atmosphere needed for low-pressure diamond synthesis. Changes in the substrate surface occurring during deposition can significantly influence diamond nucleation, growth and the adhesion of the final diamond coating [1-5].

Atomic ( $H^{\circ}$ ), molecular hydrogen ( $\mathrm{H}_{2}$ L_and carbon species cause reactions, especially with ceramics, modify certain metallic substrates, and can form intermediate layers, thus delaying the onset of diamond nucleation, growth and the coating formation.

Atomic hydrogen is essential for avoiding the formation of non-sp ${ }^{3}$ carbon. The $\mathrm{C} / \mathrm{H}$ ratio and the amount of atomic hydrogen are critical parameters. For proper diamond nucleation and growth aiso the carbon supersaturation in the gas phase must be kept relatively low in order to prevent the formation of amorphous carbon or graphite.

The diamond nucleation can be heavily disturbed by the substrate chemistry. During the early diamond growth two stages - isolated crystal and layer growth - must be distinguished [6]. Only after formation of a diamond layer can the diamond growth become independent of substrate effects. The time needed to form a continuous film depends not only on nucleation density, but also on the parameters chosen, such as carbon flux, substrate surface temperature, etc.

The very early growth period is characterized by the increase in size of the small, isolated crystals originating from the nuclei. During this stage surface diffusion of carbon to the nuclei occurs from the relatively large diamond-free substrate surface areas surrounding them. Simultaneously the activated gas phase continues to react with the substrate surface. As the diamond crystals grow together, they form larger islands which spread until the entire substrate surface is covered by the diamond coating. The substrate is no longer affected by the aggressive gas phase but it can still dissolve the diamond coating at the substrate/coating interface $[7,8]$. 


\section{INTERACTIONS AT THE SUBSTRATE SURFACES: EXAMPLES [9]}

- Diamond as a substrate permits nucleation and growth without a nucleation step (homeo-epitaxial nucleation and growth). On high-pressure diamond particles with damaged facettes the crystallographic habitus of diamond is rebuilt rapidly during CVD growth [10].

- c-BN: Hetero-epitaxial nucleation of diamond has been observed on cub-BN crystals [11].

- Silicon: Hetereo-epitaxial nucleation is difficult due to formation of a thin SiC layer prior to nucleation. Recently however special surface pretreatments have permitted epitaxial nucleation and growth $[12,13]$.

- Silicon carbide : SiC, a typical representative of a covalent bonded carbide, is practically inert to the reactive gas atmosphere used for the diamond synthesis. Having also a very low thermal expansion coefficient it is a nearly ideal substrate for diamond coatings [14].

- Ceramic materials (oxides, nitrides, etc) : Thermodynamic calculations and experiments showed that substrate surfaces of ceramics, such as $\mathrm{SiO}_{2}, \mathrm{Al}_{2} \mathrm{O}_{3}$, $\mathrm{ZrO}_{2}$, AlN, etc., can be transformed by the hydrogen or the carbon into metals, hydrides or carbides. The high reactivity with atomic hydrogen even allows chemical reactions which would not occur with molecular hydrogen. Diamond nucleation usually starts only after a stable surface layer is formed $[2,4]$.

- Pure metals : For the interactions occurring with metals the carbon species are most important. Both carbide formation and carbon dissolution into the bulk material take place.

\section{* Carbide Formation}

Refractory metals ( $\mathrm{Ti}, \mathrm{Zr}, \mathrm{Hf} / \mathrm{V}, \mathrm{Nb}, \mathrm{Ta} / \mathrm{Cr}, \mathrm{Mo}, \mathrm{W}$ ) form stable carbides in the presence of carbon or hydrocarbons. Due to their high stability and the low carbon solubility in these metals, intermediate carbide surface layers form. The layer growth rate is influenced mainly by the substrate temperature, the carbon concentration and diffusion coefficient in the particular carbide. The overall growth rate is relatively slow $[3,15,16]$.

Diamond nucleation starts readily after the surface is carburized. Scratches leading to thin edges can accelerate local carbide formation, thus promoting the onset of diamond nucleation.

\section{* Carbon Dissolution}

On metallic substrates which do not form stable carbides but which can dissolve carbon (e.g. Fe, Co,Ni [4,5], Pt [17]), carbon diffusion into the substrate occurs until the entire substrate is saturated with it. The time needed to reach saturation increases with the substrate thickness. This carbon diffusion can significantly delay the onset of diamond nucleation, since a certain carbon concentration at the substrate surface must be reached before stable diamond nuclei can be formed.

\section{INTERACTIONS AT THE GROWING DLAMOND/GAS INTERFACE}

\section{- Catalysis, of Non-Diamond Carbon Formation due to a}

High Vapor Pressure of the Substrate

Certain elements can retard or even prevent the formation of a diamond coating if in direct contact with the diamond being formed. For example iron can lead to massive non-diamond carbon deposition at the substrate/diamond interface. Only after this carbon layer is thick enough to prevent the diffusion of $\mathrm{Fe}$ from the substrate can diamond nucleation and growth start on the intermediate carbon deposit [4]. 
An excessive substrate vapor pressure can interfere detrimentally with the growth of diamond crystals. The high vapor pressure of such substrates as $\mathrm{Fe}, \mathrm{Co}, \mathrm{Ni}, \mathrm{Cr}$, etc., lead to contamination not only of the growing diamond on these substrates but also to contamination of the surrounding area, including even neighboring depositions on substrates with low vapor pressures [5]. This effect has been observed for diamond growth on refractory metals, which (except for $\mathrm{Cr}$ ) have a very low vapor pressure. There contamination by Fe, Co, $\mathrm{Ni}, \mathrm{Cr}$. etc., led to formation of numerous huge growth steps on the growing diamond crystal facettes [3,5]. Such growth steps occur when the impurities cannot be incorporated into the crystal and therefore interfere with the normal atomic attachment kinetics [18].

\section{INTERACTIONS AT THE SUBSTRATE/DIAMOND COATING INTERFACE}

In particular industrial wear protection as well as low-friction and specific structural applications of alloys can be improved by diamond coatings. The following two industrial alloy types would be of special interest for use as substrates:

\section{- Fe-, Co- and Ni-based Alloys}

Experiments with lamellar and spheroidal cast iron substrates - which are saturated with carbon -, showed that this saturation can help in achieving more rapid nucleation and growth of better adhering diamond coatings [4].

Prior to diamond deposition the substrate surfaces of pure iron or steel must be protected by "stable" intermediate layers in order to avoid the $C$ dissolution at the diamond/substrate interface, - to prevent detrimental carburization of the alloys -, and - last not least - to counteract the effects of the high vapor pressures.

Recent experiments have confinmed their feasibilty for diamond coatings by special surface treatments. Diamond coatings adhered better on carbon- and silicon-saturated cast iron alloys than on untreated iron alloys [4]. More appropriate pretreatments for reliable stable substrate surface conditions during the coating process and intermediate layers with compatible expansion coefficients sufficient to produce the required coating adhesion must still be worked out.

The detrimental effect of the prolonged heat treatment must be solved by an appropriate choice of heat-resistant steel substrates.

\section{- WC/Co-based Hard Metals}

Hard metals (WC/CO), already having excellent properties for such applications, could be even further improved by a superhard diamond coating. The sintered alloys consist mainly of WC mixed with other refractory carbides which are bound usually by a co binder (5-15 wt \%). the Co however has a detrimental effect on diamond nucleation and growth [19-22]. The adhesion problem increases with increasing co concentration in the binder and with the addition of refractory metal carbides other than WC [21]. The formation of non-diamond carbon due to the direct contact with co and to the relatively high co vapor pressure are supposedly the main reasons for the problems encountered [20-23].

Pretreatments of the hard metal to enrich locally the Co binder with Si or $B$ at the substrate surface improved significantly the diamond coating adhesion $[7,8]$.

Also applying very thin and reactive interfacial intermediate refractory metal layers ( $\mathrm{Ti}, \mathrm{Cr}$ ), on a hard metal substrate prior to the diamond deposition proved to increase the coating adhesion. These layers react at least partially during diamond deposition to form carbides and thus directly improve the adhesion, while simultaneously preventing undesirable surface reactions which would otherwise occur during deposition [24]. 
It was recently also shown that the co binder dissolves the diamond coating during the prolonged heat treatment resulting from the diamond deposition conditions. Thus the interface diamond coating/hard metal is not stable during the diamond deposition $[7,8]$. This can have also consequences on the coating adhesion.

\section{CONCLUSION : INTERMEDIATE LAYERS to control SUBSTRATE SURFACE INTERACTIONS}

of the many approaches now being proposed to deal with these various problems, that of applying intermediate layers - which was articulated many years ago [25], - might well prove to be one of the most feasible possibilities for practical industrial solutions.

The idea of putting an inert or an at least "compatible" intermediate layer between the diamond coating and the substrate - prior to the coating deposition - is thus not new. It has been successfully applied for CVD coatings on cutting tools for decades [26].

Properly utilized, this technique not only prevents substrate interactions prior to the formation of a diamond coating, it also stops the diamond dissolution at the diamond/substrate interface during deposition, and it could even help to reduce the interfacial stress problems through the choice of an intermediate layer with an appropriate expansion coefficient.

\section{ACKNOWLEDGEMENTS}

This work was sponsored mainly by the Austrian "Fonds zur Förderung der wissenschaftlichen Forschung" and was carried out at the Technical University in Vienna under the auspices of the trinational German, Austrian and Swiss "D-A-CH" cooperation on the "Synthesis of Superhard Materials".

Diamond coating

Substrate

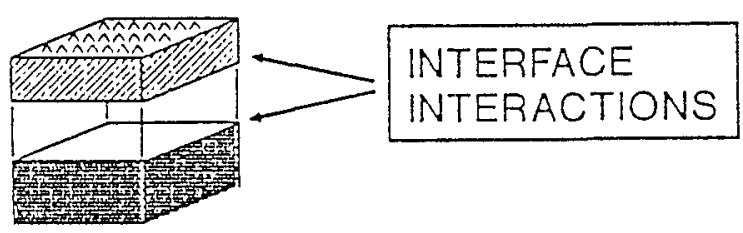

Effects due to:

\section{Substrate requirements}

Low:

- vapor pressure

- dilfusivity of elements

- solubillty for $\mathrm{C}$

- reaclivily with $H$ and $C$

- Interaction substrate / costing

- expansion coefficlent

1. Reaction gases $\left(\mathrm{C}, \mathrm{H}_{2}, \mathrm{H}^{\circ}\right)$
a) Carbon: $\mathrm{Me} \longrightarrow \mathrm{MeC}_{2} \quad$ Carbide Formations
b) Hydrogen: $\mathrm{C}, \mathrm{B} \longrightarrow \mathrm{CH}_{4} /, \mathrm{BH}_{2} /$. etc.
c) Hydrogen \& Carbon: $\mathrm{MeO}_{2} \rightarrow \mathrm{Me}$, MeC, elc.

11. Heat treatment

- Substrale Evaporation - Nucloation, Crystal Growth

- Diffusion $\longrightarrow$ Adhesion

* outwards (WC/Co-Co) Substrate $\longrightarrow$ Surface

* inwards $\quad(C \rightarrow$ Co $) \quad$ Surface $\longrightarrow$ Substrate

Fig.1: Substrate / interface requirements and effects occuring during CVD diamond deposition. 


\section{Co vapor pressure:}

delays diamond nucleation

castalyzes non diamond carbon formation

influences crystal growth

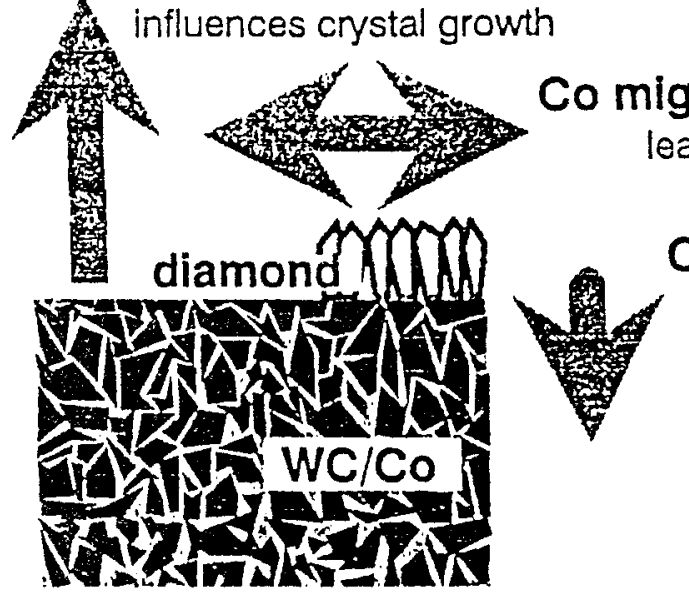

C diffusion:

delays diamond nucleation

leads to diamond dissolution

changes Co binder composition

CoNC ratio at the surface

Fig.2: Influence of the hard metal Co binder phase on the diamond deposition process [8]

Balzers AG, Liechtenstein is also acknowledged for sponsoring specific parts of this work. In particular we thank also Dr.H.Kaufmann for his personal help and interest.

Last but not least, the authors thank all students and research team members at- the Technical University in Vienna who performed the numerous experiments summarized in this review.

\section{REFERENCES}

1. B.Lux, R.Haubner: Diamond and Diamond-Like Films and Coatings NATO-ASI Series B: Physics, 266 (1991) 579-609

Edited by R.E.Clausing et al., Plenum, New York 1991

2. A.Lindibauer, R.Haubner, B.Lux: Wear, 159 (1992) 67-77

3. P.O.Joffreau, R.Haubner, B.Lux: J.Ref. Hard Metals, 7,(4),(1988) 186-194

4. A.Lindlbauer, R.Haubner, B.Lux: Diamond Films and Technology 2, No.2 \& 3 (1992) 81-98

5. R.Haubner, A.Lindlbauer, B.Lux: Diamond and Related Materials 2 (1993) 1505-1515

6. R.Bichler, R.Haubner, B.Lux: High Temperature-High Pressure Vol.21 (1989) 576-593

7. S.Kubelka, R.Haubner, B.Iux, R.Steiner, G.Stingeder, M.Grasserbauer: Diamond and Related Materials, (1994), (in press)

8. S.Kubelka, R.Haubner, B.Lux, R.Steiner, G.Stingeder, M.Grasserbauer: Diamond Films and Technology (1994), (in press)

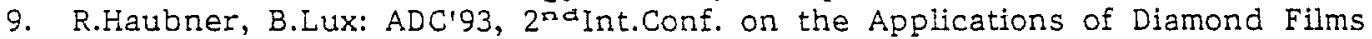
and Related Materials, Omiya Saitama, Japan, Aug.25-27, 1993, 131-138, Editors: M.Yoshikawa, M.Murakawa, Y.Tzeng, W.A.Yarbrough, MYU, Tokyo

10. P.O.Joffreat, R.Bichler, R.Haubner, B.Lux: J.Ref.Hard Metals 7, No.2 (1988) 92-97

11. R.Haubner: J.Ref.Hard Metals, 9, No.2 (1990) 70-76

12. X.Jiang, C.-P.Klages: Diamond and Related Materials, 2 (1993) 1112-1113

13. T.Inuzuka: privat communication (1993)

14. P.K.Sen, IDR, Industrial Diamond Review 52 (1992)

15. A.Lindlbauer: Doctoral Thesis, TU Vienna (1992) 
16. R.Litos, R.Haubner, B.Lux: High Temperature-High Pressure, 22 (1990) 90-118

17. S.J.Harris, D.N.Belton, A.M.Weiner, S.J.Schmieg:

J.Appl.Phys., 66, No.11 (1989) 5353-5359

18. I.Minkoff, B.Lux: "The Metallurgy of Cast Iron" pp.474-493

Editors: B.Lux, I.Minkoff, F.Mollard

Georgi Publ.Comp., St Saphorin, Switzerland (1975)

19. B.Lux, R.Haubner: Chapter 6 in "Diamond Films and Coatings"

Editor: R.Davies, NOYES Publications,

Mill Road at Grand Avenue Park Ridge, NJ 07656, USA, 1993

20. X.X.Pan: Doctoral Thesis, TU Vienna (1989)

21. R.Haubner, B.Lux: Journal de Physique, C5, 5 (1989) 169-176

22. H.Matsubara, J.Kihara: Science and Technology of New Diamond, 89-93 Editors: S.Saito, O.Fukunaga, M.Yoshiwara, KTK Scientific Publishers, Tokyo 1990

23. J.Oakes, X.X.Pan, R.Bichler, R.Haubner, B.Lux: Surface and Coatings Technology, 47 (1991) 600-607

24. S.Kubelka, R.Haubner, B.Lux, R.Steiner, M.Grasserbauer: Diamond Films'94 11 Ciocco, Italy, 25-30.Sept.1994 (in preparation)

25. H.Schachner, B.Lux, K.Stjernberg, A.Thelin, H.Tippmann: Swedish Patents, SE 8403429 and 442305 (Priority 27.06.1984)

US Patents, US 4,734,339 (March 29, 1988) and 4,707,384 (Nov.17, 1987)

26. B.Lux, H.Schachner: Proc.9 $\mathrm{m}$ Plansee Seminar (1977), Nr.34, p.315-323 